
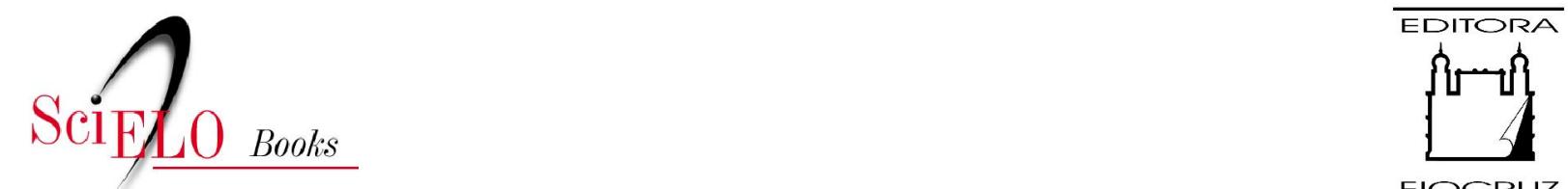

FIOCRUZ

\title{
4 - Experiência social do gênero e sexualidade
}

\author{
Simone Monteiro
}

SciELO Books / SciELO Livros / SciELO Libros

MONTEIRO, S. Experiência social do gênero e sexualidade. In: Qual prevenção? Aids, sexualidade e gênero em uma favela carioca [online]. Rio de Janeiro: Editora FIOCRUZ, 2002, pp. 69-94. ISBN: 978-85-7541-521-4. Available from: doi: 10.7476/9788575415214. Also available in ePUB from: http://books.scielo.org/id/vmnhq/epub/monteiro-9788575415214.epub.

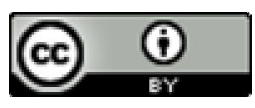

All the contents of this work, except where otherwise noted, is licensed under a Creative Commons Attribution $\underline{4.0 \text { International license. }}$

Todo o conteúdo deste trabalho, exceto quando houver ressalva, é publicado sob a licença Creative Commons Atribição 4.0.

Todo el contenido de esta obra, excepto donde se indique lo contrario, está bajo licencia de la licencia Creative Commons Reconocimento 4.0. 


\section{4}

\section{Experiência Social do Gênero e S exualidade}

Com base nos relatos do grupo de jovens pesquisado, serão descritas as trajetórias femininas e masculinas, bem como suas experiências relativas à iniciação e às práticas sexuais. Por meio do enfoque nas representações e práticas relativas à sexual idade e ao gênero, objetiva-se i denti ficar os val ores predominantes nessa população e pensar suas conseqüências para o controle da epi demia de HIV/Aids, cuja princi pal via de transmissão é a rel ação sexual .

\section{Trajetórias femininas}

Manutenção no espaço doméstico: esposa e mãe

$\mathrm{N}$ a trajetória feminina, a nostal gi a da liberdade do período da infância, quando se ocupava o espaço público (a rua) sem recei o ou 'vergonha', assinala que constrangimentos sociais vão inserindo as meninas no espaço doméstico (a casa).

As boas e saudosas recordações das brincadei ras na rua com os(as) col egas - em contraste com as lembranças negativas (controle familiar, surras e os tirotei os) - revelam esse ponto de vista:

Eu brincava muito na rua, agora tudo mudou, eu cresci, eu hoje tenho vergonha daquelas coisas que eu brincava de correr, de pique-esconde. (Irene, 14 anos)

Tenho 14 anos, sou mocinha, aí não posso ficar brincando na rua. (Verônica, 14 anos) 
Observou-se a presença feminina no mundo privado nas atividades do cotidiano. A maioria das entrevistadas revel ou assumir, total ou parcialmente, as tarefas do Iar (cozinhar, Iavar, arrumar) e os cuidados com irmãos/fil hos, mesmo no caso daquel as queestavam estudando. Grande parte já esteve envolvida em trabal hos remunerados, em período integral (operária, vendedora, costureira, doméstica, babá), mas foi demitida ou abandonou o emprego. U ma das entrevistadas afirmou: "Parei porque el es adoram explorar gente de menor". Todas as três que saí ram da escola para trabal har não continuaram nos empregos e retomaram os estudos. N o momento da entrevista, nenhuma das meninas estava empregada.

Tai s fatos ganham rel evância quando arti cul ados com a recorrência do casamento e da materni dade em idade precoce. A vida conjugal e os fil hos parecem viabilizar o projeto de constitui ção de uma vida familiar harmoniosa e feliz, capaz de fornecer apoio, segurança e companhia. ${ }^{23}$

Casamento e materni dade aparecem como val ores centrais em seus projetos de vida. Sandra, 15 anos, recorda que, quando sua mãe tem fil hos, mesmo em situações adversas (estando sem marido e já tendo gêmeos), "ela fica feliz". Letícia, 18 anos, afirma que, se perder o marido, que "é uma pessoa de val or, muito importante", tudo acaba para ela. O relato de Júlia, 15 anos, também éilustrativo:

Agora [o fil ho] vai representar um pouco de al egria na minha vida, mas eu ainda fico pensando muito em tirar e agora eu penso em ter para ter al egrias e não me sentir sozinha.

A interrupção de um investimento conti nuado na formação escol ar no universo feminino em foco relaciona-se às inadequações e aos problemas do ensino público, assi m como à ausência de um ambiente que favoreça a dedicação aos estudos. A falta da disponibilidade de livros e publicações di versas no ambiente doméstico ena comunidade- gi bis e revistas foram as leituras mais citadas entre aquel as que afi rmam gostar de ler - e de um acompanhamento das atividades escolares pelos familiares são exemplos do contexto pouco estimul anteem termos da educação formal .

As condições objetivas e o ideal tradi ci onal de identidade feminina fazem com que as perspectivas de construção de uma carreira profissional capaz de gerar ascensão social e satisfação pessoal sejam limitadas na população investigada. Vale acrescentar que as funções femininas tendem a ser associadas ao mundo doméstico, a despeito da maior partici pação da mulher no mercado de trabal ho e do crescente número de mulheres chefes de família.

${ }^{23}$ Ver o estudo de Sal ém (1981) sobre a expectativa de mul heres de camadas populares em rel ação à retribuição dos fil hos em termos de amparo e assistência econômica e afetiva. 
As atividades remuneradas das mul heres, embora possam gerar renda, em geral são consideradas complementares ao rendimento do mari do, sendo somadas às tarefas do I ar e à responsabi l idade pel a educação da prole. N o próximo capítulo, trata-se, de maneira mais detal hada, do papel feminino na vi da familiar. De qual quer modo, convém destacar o atributo social do homem como principal responsável pela fonte de subsistência da família.

O amparo financei ro ao grupo doméstico sugere nexos entre o significado de proteção e a função masculina de provedor. O relato de um rapaz de 16 anos, durante a observação de uma conversa entre um grupo de moradores, fornece mais uma confi rmação desse ponto de vista. A pós se relacionar sexual mente com uma menina virgem, el efoi chamado pela mãe da moça para assumir as despesas relativas a ela. Para 'se livrar' da situação, ele convenceu a menina de que estava interessado em outra pessoa. Val e salientar o tom de ironia do relato, indi cando uma visão crítica do garoto em relação à expectativa da mãe para que ele passasse a cui dar da menina, ou seja, assumi sse a sua proteção e subsistência.

Todas as entrevistadas com vida conjugal (quatro no total) eram sustentadas pelos maridos, jovens entre 19 e 23 anos. Vale registrar que a tendência de o casamento l egal ou união consensual ocorrer entre moças mais novas e homens mais vel hos tem sido confirmada pelos estudos demográficos.

Segundo Berquó (1998), na faixa de 15 a 19 anos, 15,6\% das moças e $3,1 \%$ dos rapazes declaram-se casados. N este mesmo período etário, 50\% das garotas casam-se com homens de cinco a dez anos mais velhos; esta disposi ção se mantém na faix xa de 20-24. Em suma, a diferença de idade na formação do par demonstra a expectativa social de que o homem usufrua uma posi ção mais estabi lizada como provedor (Bozon, 1995; Bourdieu, 1995).

Para complementar, cabe citar a conexão entre a mai or precoci dade da união conjugal e o menor nível de escolaridade. Na faixa de 15 a 19 anos, o percentual de mulheres casadas sem instrução é de $23,9 \%$, enquanto o percentual daquelas com escolaridade superior é de 4,4\%. Entre os homens de 15-19 anos, a relação é de 3,7\% para os sem instrução e de 1,6\% para aquel es com escolaridade superior (Berquó, 1998).

Vale ressal tar que o bai xo nível de escol arização do grupo contrasta com o ideal profissional relatado pel as entrevistadas. A mai oria citou carreiras que demandam longos investimentos na educação formal como direito, medicina e informática. O val or social da escolarização como um bem simból ico e as di ficul dades de real ização de projetos escolares e profissi onais permitem a compreensão deste aparente paradoxo. 
As representações sociais rel ativas ao significado da si tuação marital e da materni dade também colaboram para a interrupção dos estudos. Tais el ementos ilustram as inter-relações entre condições de existência, representações, estil os e trajetórias de vida, auxiliando o entendimento da manutenção de mul heres de grupos populares no espaço privado, conforme indica o processo de formação do núcleo doméstico das moças de Vigário Geral.

A saída da casa dos pais - decorrente da ini ciação da vida conjugal, com ou sem filhos, ou da fal ta de apoio familiar, no caso da adolescente mãe sol tei ra - tende a definir a entrada da moça na vi da adulta. Esta suposi ção tem como base a aqui sição da independência do controle familiar pel a garota e as novas funções que ela passa a ocupar na 'sua' casa.

A despeito de as atividades guardarem semel hanças, haja vista que as tarefas exercidas na casa dos pais não são diferentes daquelas realizadas no seu lar - Iavar, cozinhar, arrumar, cuidar das crianças (irmãos menores ou filhos) -, tais compromissos adquirem um novo significado. Como esposa e/ ou de mãe, a garota altera o status social de filha e torna real idade o ideal do casamento e da maternidade. As funções assumi das estimulam o abandono da escol a com mínimas perspectivas de retorno e ini bem atividades de lazer como idas a bai les, restringindo, dessa forma, a circulação da mulher no âmbito público.

Para as jovens, a saída do lar devido ao casamento e/ ou à maternidade permi te a independência do grupo familiar, a real ização de um i deal e a aquisi ção de novas funções sociais, quai s sejam, mãe e/ou esposa. A menina torna-se mulher. Essa passagem não está associada à autonomia financei ra resultante da profissional ização, comum na realidade feminina das camadas médias eal tas (Lavi nas, 1997), esi m à reprodução do papel feminino tradicional, identifi cado com a manutenção da mul her no espaço doméstico e com a atribuição masculina de subsistência.

Um segundo padrão observado nas trajetórias biográficas das jovens desse segmento social refere-se aos casos em que a gestação e/ou materni dade não são acompanhadas da convivência marital e da independência dos pais, ou seja, a menina se mantém na casa dos familiares, que compartil ham ou assumem a criação do bebê.

N essa circunstância, a passagem para a vi da adulta não é tão nítida. O fil ho tende a se tornar meio-irmão. O mais provável é que os estudos sejam interrompi dos, mas há possi bil idade de retorno. As mudanças no cotidiano, nas ativi dades de lazer e nas funções sociais, dentro e fora do lar, tendem a ser menos significativas. 
Há casos em que a vida conjugal se inicia na casa dos familiares, mas, com base no rel ato de informantes, a expectativa de o marido (homem) assumir o papel de provedor se mantém. Quando esse papel não é cumprido, os familiares cobram do rapaz, podendo até expulsá-lo da casa.

\section{Rel ações com o comércio il egal de drogas}

O abandono do lar, em decorrência de problemas com os pais (agressão doméstica, alcoolismo, descuido), também configura uma terceira maneira de marcar a independência do grupo familiar das meninas. ${ }^{24}$ Observaram-se el ementos comuns nas trajetórias das moças entrevistadas que saíram de casa em função de conflitos familiares.

Com base na biografia de seis, entre as dezoito jovens pesquisadas, foi possível notar um nexo entre as situações de desorganização do grupo doméstico - agressões, abuso sexual, abandono e uma tendência à aproximação com o comércio ilegal de drogas. A inserção nesta atividade gera autonomia financei ra, independência do grupo familiar e formas de defesa (acesso a armas e respeito), apresentando-se como uma aventura e/ou saída diante das dificul dades da vida. Os depoimentos são revel adores:

Fui morar com umas amigas (...) me divertia bastante (...) eu era meio doida, aí eu levava a carga e todo final de semana eu recebia cem reais. ${ }^{25}$ (...) Um dia, quando eu voltei daqui, aí fui pra lá, encontrei os irmãos das minhas colegas morto. Aí eu fiquei com medo e pedi pra minha mãe pra voltar. (Valéria, 17 anos)

Teve hora na minha vida que eu passei muitas dificuldades, entrei para o tráfico, depois eu vi que não estava dando certo, que ia acabar morrendo. Aí eu saí e coloquei a minha cabeça no lugar (...) muitas vezes eu estava dentro do carro e o carro foi metraI hado, [aconteceu] de eu rezar enenhuma bal a pegar em mim, de ver o cara que tava do meu lado morrer. (Letícia, 18 anos)

No universo do tráfico, em que predomina o ethos masculino (Zaluar, 1985;1994), as mulheres ocupam diferentes papéis: consumidora, esposa de traficante e profissional. Como consumidoras dependentes, submetem-se a favores di versos, que incluem sexo, carregamento de armas e drogas ilícitas. Nessa posição, perdem os víncul os familiares,

\footnotetext{
${ }^{24}$ Esses problemas não estão restritos aos setores populares urbanos, acontecendo em todas as classes sociais. Todavia, as anál ises acerca da violência doméstica (Heilborn, 1996; Soares, 1996; Brandão, 1998) chamam atenção para as singularidades do seu significado entre os diferentes segmentos sociais.

${ }^{25}$ O val or do salário mínimo no Brasil, em outubro de 2001, era de R\$181, cerca de U \$ 67.
} 
não conseguem cuidar dos filhos, morrem em ações arriscadas ou acabam presas. Um dos jovens entrevistados envolvidos no tráfico relatou:

várias se vendem também por cocaína (...) el as esquecem [o uso da cami sinha], só quer saber da ambição do pó da cocaína (...). Agora o homem não, o homem já pensa logo. (Pedro, 18 anos)

No papel de namorada ou esposa 'oficial', 'menina de fé' dos líderes, as moças desfrutam do acesso aos bens de consumo val orizados social mente (vestuário, perfumes), ganham status, respei to e uma certa proteção na comuni dade. O uso do prestígio da posi ção de 'viúva debandi do' no jogo de sedução com os rapazes ilustra este ponto de vista. O vínculo amoroso com pessoas 'envol vidas no movimento' 26 tem seu preço. O companheiro tende a morrer cedo ou ser preso; além disso, há o risco de vingança de policiais e de traficantes inimigos. Todavia, os benefícios materiais esi mbólicos, combinados com a assi metria de gênero, que caracteriza a cultura viril do comércio il egal das drogas, dificultam o rompimento dessas meninas com o universo do tráfico.

A garota da favel a hoje escol he, ou vira mulher de al guém ou trabaIha pro tráfico (...) as que trabal ham não duram muito porqueficam sabendo demai s. Quando vira 'mulher de fé' é mel hor porque todo mundo respeita (...) Tá vendo este anel é igual a cartão de crédito, com el e faço compra na venda e pego quanto pó eu quiser na boca. Todo mundo sabe quem sou eu. (Jornal do Brasil, 16/08/1998)

As meninas são seduzi das por homens mais vel hos, geral mente pessoas que elas admiram, [por exemplo,] o professor, mas predomina o bandido. Estar com el esi gnifica poder, ganhar roupas, ir ao cabelei reiro, eles compram as meninas, elas ficam com uma dívida, ou seja, tem que ficar disponível para eles. (líder comunitário)

É interessante comentar que os casos amorosos com pessoas 'envolvidas', citadas pelas jovens entrevistadas, mesmo resultando em morte ou prisão do namorado, são lembrados como grandes paixões que não foram esqueci das.

Ainda que de forma vaga, esse dado aponta para uma possível romantização do papel de bandido que faz justiça com as próprias mãos, é capaz de impor respeito ereal izar o sonho de consumo de 'suas' mulheres. A pesar de a mai oria do grupo pesquisado condenar as atividades dos traficantes devido à violência, à busca de dinheiro fácil e ao acesso à 'mulé', frente àvisão negativa da polícia, ài ineficácia das instituições judiciárias e ao descaso do poder público, o bandido assume o papel de benfeitor e protetor.

${ }^{26} \mathrm{~A}$ expressão "envolvida no movimento" refere-seà participação no comércio il egal dedrogas. 
Como profissionais do tráfico, na mai oria dos casos, as garotas ocupam posições inferiores como 'foguetei ra' (sol ta fogos quando a polícia chega) e 'avião' (leva a droga). Um líder comunitário rel atou:

O papel da mulher no crime é de segunda categoria, é raro ver uma mul her armada, geralmente el as jogam 'pisa' [roubam e escondem debaixo da saia], fazem 'chorra' [roubar sem que perceba] e fazem mula [levar a droga].

U ma recente pesquisa sobre a população carcerária feminina do estado do Rio de Janeiro (Soares et al ., 2001) fornece uma caracterização complementar deste fenômeno. A investigação atestou o crescimento do número de mul heres presas por envol vimento com o tráfico de drogas, que passou de 32\%, em 1988, para 56\% em 2000.

A mai oria das encarceradas por esse delito $(78,4 \%)$ revela que sua prisão ocorreu por estar presente em uma situação que envolvia outras prisões ('bucha'), por uso de drogas ou pela partici pação em cargos subalternos no tráfico ('mula', 'avião', 'vapor'). Uma minoria se referiu a funções mais hierárquicas como: "abastecedora/distribuidora, traficante, gerente, dona de boca ou caixa/contabi lidade" (Soares et al ., 2001:26-27). ${ }^{27}$

Diante da identidade social feminina associada à noção de fragilidade - expressa pela fal a de um rapaz "mul her não agüenta pancada se for pega (...) é fofoqueira" (Jornal do Brasil, 16/6/98) - as meninas que se profissionalizam tendem a acionar o modelo masculino, agressivo e heróico, vestindo-se e fal ando como homens para serem respeitadas e aceitas naquel e grupo. Segundo a mesma reportagem, em uma instituição de recuperação, uma mãe levou cuecas para a filha, a outra mãe se referia à filha pela versão masculina do seu nome.

As descrições apresentadas revelam semel hanças com a análise de Zaluar (1994) sobre o papel feminino em um cenário ordenado pelo tráfico. A autora destaca: a função secundária da mulher na atividade profissional; a exposi ção ao estupro daquel as próximas ao ambiente dos bandidos e com grande número de parceiros e/ou com práticas homoeróticas; a cumplicidade da esposa oficial do bandi do; a força moral da mãe; a reprodução do papel tradicional (dona-de-casa, esposa e mãe) e a incorporação dos atributos masculinos por uma minoria que ingressa nesse universo viril.

27 Segundo Soares et al. (2001), o número de mulheres presas é muito pequeno quando comparado ao contingente de homens encarcerados. Pondera-se que o aumento da partici pação feminina em crimes não pode ser interpretado como uma adesão expressiva à criminalidade, é preciso levar em conta uma possível diminuição dos níveis de condescendência da justiça criminal com as mulheres infratoras e as mudanças nas políticas de segurança pública na década de 90 no Rio de Janeiro. 
Ao adotar um comportamento masculino, visando ao respei to e à proteção, a menina nega a identidade feminina tradicional. N egando a condição de mulher, ela não deixa de afirmar que a feminilidade deve ser exercida no âmbito doméstico. De qualquer modo, é possível supor que a entrada das meninas no mercado 'profissi onal ' do poder ilegal não permite mudanças na visão tradi ci onal do papel feminino, tendo em vista o fenômeno da masculinização, a não permanência (transitoriedade) das mul heres nessa ati vi dade e os li mites da ascensão feminina a determinados postos hi erárqui cos nessa área.

As seis entrevistadas queafirmaram ter trabal hado para o tráfico exerciam funções periféricas. Diante dos riscos de morte, prisão e perda de amigos e namorados, el as deci di ram sai r e constituir uma família (casamento e maternidade). Assim como a posição de mul her detraficante, tal movimento sugerea atual ização ea reprodução dos papéis sociais mascul inos efemininos, em uma perspectiva assimétrica, quetambém seexpressa no significado de proteção por meio de uma oposição complementar.

O universo masculino se conecta com a força física, o sustento econômico pela ati vi dade remunerada e o domíni o do espaço públ ico, ao passo que o universo feminino ocupa o mundo doméstico, organiza o Iar, cuida da prole e fornece esteio moral.

Cabe, por fim, citar que a descrição dos papéi s masculinos e femininos, assi nal ados até então, guarda semel hanças com o estudo de $M$ aher (1997) sobre as diferenças de gênero na estruturação do mercado informal nas economias capi tal istas pós-industriais. Com base na anál ise do mercado ilegal de drogas e na experiência de trabal ho com usuárias de droga, a autora demonstra que as mul heres ainda tendem a assumir funções femi ninas e a receber menos que os homens, particul armenteentre os grupos mais empobreci dos e margi nal izados.

\section{Trajetórias masculinas}

\section{Ocupação do espaço público: profissional e provedor}

A trajetória masculina é distinta da feminina e a ela complementar. Alguns garotos disseram que ainda se sentiam crianças, sugerindo que o adiamento da entrada na vida conjugal - entre os quatorze entrevistados nenhum estava casado - e a permanência no âmbito público podem gerar um prol ongamento da percepção da infância no universo masculino; mesmo sendo acompanhada da conscientização de novos compromissos e do abandono do ensino formal. 
N ão obstante a aproximação com o relato do grupo feminino sobre as lembranças boas e ruins (surras e tiroteio) da infância, observaram-se variações de gênero relativas às formas de ocupação do espaço público. A riqueza das citações das brincadei ras de rua (futebol, bola de gude, pião, pegar docee pi pa) eo val or atri buí do ao trabal ho exempl ificam o diferencial de gênero.

Entre os rapazes, observa-se que a saí da da infância não corresponde à li mitação da ocupação do mundo públi co e si m a al terações na percepção desse espaço, devido às pressões soci ai s para assumir atos e compromissos eà entrada no mercado de trabal ho. $\mathrm{O}$ início da vida adulta mascul ina guarda, assi m, uma rel ação com a mudança de si gni fi cado da rua. M esmo mantendo o significado de lazer (futebol, baile), o espaço público passa a representar a concepção de local de trabal ho, de responsabilidade e de busca da atividade remunerada - "quando a gente começa a trabal har deixa de ser criança".

A expressão 'pegar responsabilidade' sugere a internalização da expectativa social da função mascul ina, referente ao compromisso pela subsistência da família, assim como a citação do termo 'ser mai s cabeça' - regi strado em outros estudos sobre grupos popul ares - incorpora "uma forte conotação moral positiva, abrigando os si gnificados de responsabili dade, intel igência e conduta moral" (Heil born, 1997:308).

Tais qualidades são requisitos importantes para o papel social de provedor e protetor da mulher e se opõem ao descompromisso (molecagem, 'ficar zoando') dos tempos de criança. Isto significa dizer que a falta de investimento na educação formal e a não participação nas tarefas domésti cas são percebi das pel o grupo como tendênci as 'naturais' da trajetória masculina, reproduzi das e atual izadas (Bourdieu, 1995).

Ainda que presente nos relatos das meninas, a importância do trabal ho - para ajudar nas despesas da casa e adquirir bens de consumo aparece de forma mais recorrente entre os homens. No momento da entrevista, além de estarem mais ausentes da escola do que as garotas, vários, em contraste com apenas duas meni nas, recebi am remuneração. Entre as ati vi dades, preval ecia o trabal ho ou a partici pação nas organizações comunitárias locais; al guns recebiam auxíli o-desemprego ou atuavam no comércio ilegal de drogas.

As experiências profissionais se diferenciam daquel as das meninas pela função, mas se aproximam pela variedade (mecânico, engraxate, gráfico, flanelinha, feirante). Realizadas em tempo integral, não geram vínculos, qualificações ou estímulo, com exceção da profissionalização em informática, proporcionada pela organização co- 
munitária local. Entre aquel es que assumi ram funções de coordenação nas instituições não-governamentais locais, foi enfatizado o papel do trabal ho na transformação social. Eles acreditam que suas atividades podem mudar a imagem da favel a e mel horar a vida dos moradores.

Eu sou o coordenador desse Centro Cultural, éum trabal ho social, é uma responsabilidade muito grande fazer projetos para trazer pra aqui. (...) Acho que [a organização] está conscientizando um pouco a galera, tem meninos que andavam descalços [e] agora andam de chinelo, passam a se cui dar mais. (Rodrigo, 18 anos)

N ovaes refl ete sobre os efeitos da ação de mediadores - organizações civis e igreja, entre outros - na trajetória social de jovens de camadas populares urbanas. Para a autora, movimentos (como Viva Rio e GerA ção) e organizações (como a Casa da Paz e o Grupo A fro-Reggae), orientados pel a i déia de ci dadani a e sol idari edade, têm contribuído para a ampliação de alternativas de vida de alguns jovens moradores em termos de "ressocializar, reconverter trajetórias, reafirmar valores" (N ovaes, 1997:150), reduzindo os efeitos perversos da 'cul tura do medo'. Conquanto reconheça as restrições, conclui:

Podemos dizer que esses jovens aportam um capital simbólico para toda a comunidade (...) e, em conseqüência, são questionados os limites que interiorizam (e tornam naturais) os mecanismos de exclusão e segmentação social. Parte deles se torna 'profissionais dos Projetos' adquirem uma competência específica para um outro ti po de mediação entre os jovens das áreas pobres e as instituições externas. (N ovaes, 1997:153)

Duarte et al. (1993) apresentam uma visão menos otimista sobre a intervenção de organizações vol tadas para a promoção social de classes populares, referindo-se ao fato de que elas se comprometem com um projeto de conversão à cidadania pela via da racionalização. Segundo os autores,

a ordem liberal-individualista não pode prescindir da construção do Estado (...) a 'conversão' pela racional ização nunca é suficiente para a produção de 'cidadãos': impõe-se a reprodução pela disciplinarização. (Duarte et al.,1993:17)

As análises de N ovaes e Duarte et al . estimulam uma discussão sobre o papel de mediação das organizações comunitárias na trajetória de jovens de camadas populares. Tal empreendimento demandaria um exame dos fundamentos das propostas e de suas repercussões na real idade em questão a partir da caracterização de seus desdobramentos futuros e dos diferentes impactos entre os gêneros, estando al ém do escopo do presente estudo. 
Considerando, no entanto, que 27 (entre os 32 rapazes e moças) parti ci pam ou parti ci param de al guma ati vi dade nas insti tuições comunitárias locais, val e registrar impressões gerais col hidas durante o trabaIho de campo:

- as motivações dos(as) jovens para entrar nessas instituições são diversas: curiosidade, 'pra matar o tempo', 'preencher a mente', 'ganhar um troco', adqui rir uma qual i ficação; mesmo aquel es que nunca partici param - al egando fal ta detempo, desi nteresse, 'preguiça' - têm uma visão positiva das iniciativas e admitem possibilidade de participação futura;

- a diferença mais destacada entre aquel es que freqüenta(ra)m em relação aos que nunca partici param refere-se ao gênero: os homens criam mais víncul os nas organizações e são mais atingidos pel as propostas de profissi onal ização, sugerindo, mais uma vez, o maior envolvimento mascul ino com o trabal ho remunerado;

- o recurso financeiro ofereci do pelas organizações é dividido entre as despesas da casa e os gastos pessoai s (vestuári o, lazer); essa evi dência corrobora o argumento já apresentado sobre a rel ação entre moti vação para a ati vi dade remunerada e investi mento em bens de consumo. Convém citar que o vídeo-documentário Formou o Bonde (1994) sobre sexual i dade e Aids, real izado na favel a de Vigário Geral, registra os cuidados de rapazes e moças com a aparência durante a produção para o baile, como ida ao cabel ei rei ro, passar creme no corpo, escolha da roupa e do tênis etc.;

- as ativi dades não geram necessariamente qual ificação, inserção profissional e/ou mudança no padrão de vida; no entanto, há casos de possi bi lidades concretas de profissi onal ização, evidenciadas nas ativi dades no campo da informática, da indústria delazer e de coordenação de programas na organização comunitária;

- os profissionais que atuam em serviços de assistência questionam a não adesão dos moradores aos programas oferecidos e a acomodação e vitimização dos mesmos; tais dados sugerem o conflito de lógicas eval ores já apontado na literatura (Leal, 1995; Duarte et al., 1993);

- a comuni dadetem um visão positiva das organizações comunitárias pel o fato de el as contri buírem para mudança da imagem negativa da favela e oferecerem alternativas: "Vigário Geral sempre teve a fama de ser vi olento e agora el es [a organização] transmitem que tem cultura aqui dentro", afirma um dos entrevistados; 
- os líderes do tráfico l ocal se informam sobre o funcionamento das organizações comunitárias e convocam seus coordenadores para conversar, desta forma fomentam a caracterização de benfeitor do traficante, reforçando o papel mascul ino de dominação, controlee proteção da área. Vale dizer que, segundo relatos, os coordenadores das instituições não aceitam o dinheiro do tráfico.

É interessante pensar que um dos motivos para a tolerância e a cordial idade entre instituições com princípi os tão diversos pode ser decorrente da não interferência das organizações comunitárias na ação do comérci o i legal de drogas. Isso si gnifica dizer que as instituições da sociedade civil pretendem ser uma alternativa ao tráfico. M esmo permitindo mudanças na trajetória de al guns jovens, suas ações parecem não enfraquecer de forma significativa o sistema de funcionamento das atividades il egais, que se amplia e envolve pessoas cada vez mais jovens.

A compreensão das repercussões das organizações voltadas para educação, saúde e cultura de comuni dades populares urbanas e das suas rel ações com o tráfico é um tema amplo e complexo, levantado apenas com base em relatos e impressões. Este rápi do registro pretende estimuIar desdobramentos e debates futuros.

\section{A sedução do tráfico}

Ainda no campo das atividades remuneradas, é preciso considerar os apelos do comércio ilegal de drogas. Em um universo de baixo nível socioeconômico, a participação nessa atividade pode significar poder de consumo, acesso às estratégias de defesa pessoal e aquisição de status social.

Quer dizer, o garoto de família pobre, sem recursos e perspectivas de mudança de padrão de vida torna-se uma pessoa temi da e respeitada com condições de consumir os produtos das cl asses abastadas, conquistar o objeto de desejo feminino, enfrentar a polícia, presentear eapoiar a sua comunidade. A força moral, bélica e financei ra proporcionada pelo tráfi co representa, assi $m$, uma forma de 'proteção' contra a escassez dos bens materiais e si mból i cos da cultura dominante, inacessíveis aos segmentos populares. ${ }^{28}$

${ }^{28} \mathrm{~N}$ a entrada para o universo do crime deve-se também considerar a importância das idéias de honra, hierarquia e reciprocidade. Tal ponto de vista não será abordado no presente trabalho, mas pode ser confirmado pela análise de Alvito (2001) acerca da trajetória de vida de chefes do comércio de drogas de Acari e de dados da literatura sobre outras favelas. 
A adesão de parte do grupo ao tráfico de drogas sugere que, em termos de profissional ização e mobilidade social, a geração adulta não representa um modelo positivo a ser seguido. Zaluar (1994; 1997), ao anal isar essa temática, ressal ta que existe um conflito entre a val orização de uma ética do trabal hador, que é moral mente superior à do bandido, percebi do como vagabundo, eà vi são negativa do trabal ho, concebido como escravi dão ou coisa de 'otário' , devido à intensa carga horária, aos bai xos salários e à submissão aos mandos dos patrões.

A autora sustenta que nesse universo há uma interpenetração de lógicas culturais, na qual a matriz holista vem sendo confrontada com a matriz moderna. Informada por uma reflexão crítica das teorias sobre violência urbana, destaca que o crescimento do mercado i legal de drogas expressa o rompimento dos Iaços sociais. $\mathrm{N}$ as suas pal avras:

A fragmentação das organizações vicinais e familiares facilitou o domínio dos grupos de traficantes no poder local, que, por sua vez, aprofundou a ruptura dos laços sociais dentro da família e entre as famílias da vizinhança, acentuando o isolamento, a atomização, o indi vidual ismo. (Zaluar, 1997:41)

Em uma abordagem si milar, Velho (1996) argumenta que as desigual dades sociais do mundo moderno associadas à massi ficação de costumes, à incapaci dade das instâncias governamentais para mediar e promover o bem-estar da população eà crise de val ores que ori entam as relações sociais, em especial as expectativas de reciprocidade, têm influenciado a combinação de lógi cas diversas. Para o autor, a partici pação de jovens de classes trabal hadoras urbanas no tráfico ilustra este ponto de vista.

Certamente, o crescimento e a difusão de val ores indi vidualistas na sociedade brasilei ra não significaram o fim da hierarquia. Encontramos coexistência e combinações das duas visões de mundo, com matizes e nuanças (...) no próprio mundo do crime registram-se atitudes e comportamentos que podem estar reproduzindo mecanismos de patronagem, ao lado de manifestações de um individualismo frenético. (Velho, 1996:18)

A questão da interpenetração de lógicas culturais, ou melhor, a apropriação do ideário moderno pel os segmentos populares urbanos está presente na reflexão de Vaitsman (1997; 1998) sobre as alterações na família e nas relações de gênero entre mul heres de baixa renda a partir do processo de modernização. Em seu ponto de vista, as mudanças na esfera da cul tura - decorrentes de transformações no âmbito econômi co, institucional e político - produzem impactos diferenciados nos variados grupos soci ais. Simul taneamente, estas modi fi cações geram si mi lari da- 
des na medida em que os novos contextos são, mesmo que em parte, compartil hados pel os diversos segmentos. A autora explica:

Da perspectiva do sujeito, a parti ci pação em distintos contextos e jogos discursivos implica simultaneamente em produção de similaridade e diferença, pois ele atua em novos universos comuns, dos quais ao mesmo tempo se diferencia. Sobretudo na cena urbana, ele toma parte simultaneamente de mundos diferentes que, no entanto, se interpenetram. (Vaitsman, 1997:307)

As refl exões em torno da interpenetração das lógi cas cul turais revelam o caráter dinâmico, plural, produtor de (re)arranjos diversos da vida em sociedade, principal mente no espaço urbano contemporâneo permeado pela coexistência de discursos e práticas de segmentos variados que se renovam continuamente (Vel ho, 1994).

De acordo com Giddens (1991), uma das características das "condições de moderni dade" refere-se às impl icações da refl exivi dade da vi da social, haja vista a dimensão de renovação, instabilidade e revisão do conhecimento e das práticas sociais, contraposta ao sentido de permanência e de resistência à mudança das soci edades tradi cionais.

Ao buscar el os de conexão entre tal pressuposto e os dados das trajetórias de rapazes e moças de Vigário Geral, observa-se a presença, pouco expressiva, de relatos identificados com o ideário moderno. Preval ecem nas fal as e nos dados das biografias evi dências da atual ização de traços do i deário tradi ci onal como o val or da rede de parentesco, vizinhança e local i dade e a assi metria dos gêneros na construção da identi dade social desses jovens.

Existe uma tendência em concordar com o argumento da predominância de um caráter hol ista na popul ação investi gada, conforme proposi ção de Duarte (1988). O que não significa negar as repercussões do ideário moderno entre as camadas populares - já que a noção de predomínio não implica exclusão ou impossibilidade de convivência entre lógicas di versas - nem desconsi derar indicações de mudança no val or do trabal ho entre a população investigada, particul armente entre os jovens envolvidos no tráfico.

\section{Casamento e paterni dade: um projeto adiado}

A paternidade e a criação de um núcleo familiar harmônico também integram o projeto de vida dos rapazes, mas, em comparação com as meninas, são mais tardios. Os casos de gravidez não planejada não acel eram, necessariamente, o convívio conjugal: 
Eu tenho um filho, eu engravidei uma menina (...) ela resolveu ter o filho, eu preferia que ela tivesse tirado. [Já ocorreu com você outros casos em que a mul her engravidou?]Já e as pessoas ti raram ou perdeu o filho. (Álvaro, 18 anos)

Rolou, aí ela tomou remédio e tentou tirar. Ficou tudo resolvido, tiraram e nunca tive filhos. (Rodrigo, 18 anos)

Quando a gestação é manti da e não há vínculo amoroso, na visão masculina, a mulher tenderá a assumir sozinha a criação do(a) filho(a). Alguns rapazes citaram o compromisso com a criança: "vou tá ali cumprindo com a minha obrigação, mas ela vai pra um lado e eu pro meu, né" (Pedro, 18 anos). N ão foi notado qual quer tipo de constrangimento social provocado pel a gravidez não pl anejada. Deve-se considerar que a concepção é um sinal de afirmação da virilidade frente a si mesmo e aos pares, bem como de realização do papel de reprodutor no grupo doméstico.

Em sua pesquisa com homens de 17 a 45 anos com baixo poder aqui sitivo, Villa (1998) aprofunda esta discussão, assinalando dilemas na construção da identidade masculina relacionados à prática sexual e à paterni dade. $\mathrm{O}$ autor destaca a contradição entre o incenti vo ao exercício de sexual idade autônoma, que motiva a regulação da fecundidade no momento de constituição da união conjugal e o valor social e cultural da paternidade (papel de reprodutor) no âmbi to doméstico. $O$ controle da sexual idadee da reprodução por parte dos homens também entra em confl ito com a percepção do poder femi nino em rel ação à regul ação da gravidez.

É interessante justapor a visão mascul ina à experiência feminina. De acordo com as entrevistadas, a interrupção da gravidez significou tristeza, sofrimento, abandono e medo da infertilidade:

Ele me largou eu tinha quatro meses de gravidez, eu sofri muito com el e, el e me batia, eu grávi da apanhava muito. (M aria, 15 anos)

A pessoa vai tirando uma porção de vezes, o útero vai ficando fraco, aí quando quiser ter filho mesmo não vai ter. (Helena, 19 anos)

No início eu contei pra el e e ele fal ou que o fil ho não era dele, (...) quase sempre o homem não quer o filho, mas tem homem que gosta. (Júlia, 15 anos)

A mbos os sexos admitem que uma criança pode unir o casal, contudo, observam que ela não garante a continuidade do víncul o conjugal se não houver interesse dos dois: "acho que gravidez não prende o homem, não" (Teresa, 18 anos); "tem uns que gostam; outros ficam duvidando se o filho é seu" (José, 15 anos). 
Leal \& Lewgoy (1995) enriquecem essa discussão ao concluírem que garotas de grupos populares, diante de um sinal como atraso da menstruação, tendem a tomar chás ou remédios abortivos para a regra descer, caso não identifiquem condições familiares, morais e materiais favoráveis à geração de uma criança. As medi das adotadas não são percebi das como abortivas, pois não se chega a reconhecer a gravidez, mas um ti po de desordem. Isto é, "sem o reconhecimento social da gestação não há embrião, nem feto e nem ao menos gravidez" (Leal \& Lewgoy, 1995:70). O reconhecimento social da gravidez geral mente ocorre quando se aval ia a viabilidade de assumir o projeto de formação de uma nova família.

\section{Rotei ros sexuais: o contraste entre os gêneros}

Gagnon (1990) analisa as fontes sociais do processo de aprendizagem da conduta sexual, introduzindo a concepção de cenário sexual . Sal ienta a importância da identifi cação e da compreensão das narrati vas culturais implícitas e explícitas que estruturam as práticas sexuais, bem como dos el ementos objetivos e subjetivos que integram a experiência sexual, como gênero, faixa etária, espaço, expectativas, sentimentos, rel ações de poder, entre outros. A apreensão de tais aspectos, no entanto, impõe uma série de desafios metodológicos, assi nal ados por Parker et al. (1995) e Lhomond (1996).

Para minimizar as dificuldades impostas pela temática e pel o fato de a entrevista ter si do conduzi da por uma pessoa 'de fora', a aproximação com o universo investigado foi feita com intermédio de mediadores da própria comunidade. Os encontros foram real izados nos locais defi nidos por el es(as) e complementados com observações de contextos de sociabi lidade e reuniões com jovens moradores. Procurou-se estabel ecer ligações com el ementos do espaço 'conhecido' (de dentro, familiar), visando a alguma identificação com as expressões culturais locais.

A pesar de os(as) entrevistados(as) terem manifestado cooperação e interesse - a mai oria assinal ou a oportuni dade de aprender e fal ar de assuntos da vida sobre os quais el es/ el as não têm com quem compartiIhar - cabe regi strar a ocorrência de certas reações de surpresa e constrangi mento em relação a questões sobre sexo.

Esta impressão foi confirmada pelo rel ato de al guns depoentes. Tal fato sugere que a ênfase no di ál ogo e na probl emati zação da sexual idadepresente no discurso moderno sobre direitos sexuais e reprodutivos e (des)igual dade dos gêneros - não é comum nessa real idade. De qual quer modo, segundo indicam as fal as a seguir, observa-se que, no encontro, foi 
possível estabel ecer al gumas conexões rel acionadas a representações do sentido de proteção, como confiança para expressar idéi as e sentimentos, al ém de uma associ ação com laços de vizinhança.

As coisas que falei acho que não teria coragem de fal ar com uma pessoa que já conheço há um tempão. (Otávio,19 anos) (grifo meu)

Pel o menos a gente tem uma pessoa que faz umas perguntas e eu desabafo, a gente não vai contar isso pra ninguém... As coisas que eu não pude conversar com ninguém eu conversei contigo. (Valéria,17 anos)

N unca tive esse ti po de conversa com ninguém. (Verônica,14 anos)

Fez pergunta sem maldade. (Denise, 13 anos)

Você foi perguntando as coisas como se fosse uma pessoa muito minha amiga e eu fui relaxando, contando e tirando o sufoco de dentro de mim. (M aria, 15 anos) (grifo meu)

A pesar das restrições apontadas, as informações obti das permitiram a apreensão de aspectos da ativi dade sexual, capazes de orientar reflexões sobre as políticas preventivas e de estimular investigações futuras.

\section{Iniciação sexual}

Das 18 entrevistadas (a mai oria de 14 a 18 anos), 8 declararam ser virgens. Seus namoros envolvem beijos, abraços e passei os. Al guns relatos apontaram para a associação da figura masculina com a noção de domínio e iniciativa em relação ao sexo: "quando a gente namora na casa deles, eles querem mandar na gente" (Denise, 13 anos); "a gente conversa, mas el e nunca me forçou, já tem sete meses que a gente namora" (Verônica, 14 anos).

$\mathrm{N}$ a busca de indicadores que sugerissem características comuns na trajetória desse grupo, di ferenciando-o do grupo de meninas com experiência sexual, foi possível identificar al guns pontos semel hantes que se tornaram expressivos quando analisados de maneira integrada. No grupo das sem experiência, há mai or control e e preocupação das mães. Duas situações exemplificam essa afirmação: ao ser avisada de que não poderia partici par da entrevista, uma mãe indicou desconforto, comentando: "é segredo, é?"; outra mãe pediu que eu aconsel hasse sua fil ha e comentasse seus comportamentos e dúvidas após a entrevista.

A permanência na escola se constitui um fator recorrente neste grupo, sendo ilustrada na seguinte fala: “tem várias garotas que eu conheço de 15 anos, tudo grávida em vez de estar estudando, curtindo a 
vida" (Irene, 14 anos). O não envolvimento com o tráfico de drogas, a menor freqüência aos bail es e a maior partici pação em ati vi dades recreativas ligadas ao mundo infantil e ao esporte - como pique, queimado, bicicleta e futebol - foram el ementos que também preval eceram entre as meninas que afi rmaram ser virgens.

$\mathrm{N}$ ão foram observadas di ferenças importantes na faixa etária e no desenvolvimento físico do grupo sem e com iniciação sexual, com exceção de uma garota virgem que, al ém de ter porte miúdo e seios pequenos, tinha o hábi to de chupar o dedo. Chama a atenção que a idade da ini ciação sexual do grupo pesqui sado (preval ece a fai xa de 13 a 15 anos) está abai xo da média do país: 16,7 entre os homens e 19,5 entre as muIheres, ${ }^{29}$ sugerindo estudos subseqüentes capazes de identificar a idade do início da vida sexual nos diferentes grupos sociais.

Os argumentos apresentados indicam quetai s investigações devem enfocar a inter-rel ação entre adiamento do início da vida sexual , estrutura e control e do grupo familiar, local de moradia, escol aridade e espaços de interação social. Ainda que não se tenha incluí do uma etnografia dos bai les, com base na literatura, ${ }^{30}$ é possível sugerir que o baile - espaço de convivência e sociabili dade, caracterizado pela ausência da vigilância familiar e da comunidade, pela exposição de coreografias e estéticas corporais e pela grande concentração de jovens - favorece o relacionamento entre os pares e a experimentação sexual.

O baile foi a atividade de lazer mais citada entre meninos e meninas com experiência sexual. Conforme mencionado, entre as moças 'virgens', as ativi dades recreativas, em geral, ocorrem dentro da comuni dade. O contato com outros cenários se dá por meio da escola, que é próxima ao local de moradia. Mesmo que as unidades de ensino estimulem a convivência social, tais espaços também geram uma forma de controle social, 'protegendo' da interação com os demais universos. Em suma, o baile representa a esfera da 'rua' (descontrole, anonimato, 'sexo arriscado') e se contrapõe à proteção da casa/comuni dade (conhecido, familiar, 'sexo sem risco').

29 No grupo feminino, a análise por coorte aponta para uma diminuição pequena na idade mediana da iniciação sexual: 18,8 no grupo de 20-24 e 20,7 no grupo de 45-49. Com relação à escolarização, na faixa de 20-24, a idade média da primeira relação do grupo sem nenhuma instrução foi de 15,6 e no grupo com 1 a 3 anos de instrução de 17,9. A idade média entre as mul heres de 20-49 anos sem nenhuma instrução é de 17,6 e com 12 anos ou mais é de 22,4 (Benfam,1996:77).

${ }^{30}$ Ver Vianna (1988), Cecchetto (1997), Souto (1997), Cunha (1997). Os(as) autores(as) tendem a destacar as diferenças entre os bailes. N a definição de Ceccheto (1997:99-100), no baile de 'embate', há menor controle das brigas; no baile normal, a briga é organizada e no baile da comunidade, não existe confronto. 
Em concordância com essa descrição, sugere-se que a interação limitada com outros espaços sociais da ci dade - potencial izada pela geografia da favel $a^{31}$ e pela vigilância da rede familiar e de vizinhança integra os fatores de controle do comportamento feminino que colaboram para o adiamento da iniciação sexual.

Tal pressuposto poderia ser enriqueci do por investi gações posteriores, em uma abordagem comparativa da experiência sexual e de gênero de jovens que não estão sujeitos a redes pessoais de controle e socialização, como é o caso daquel es que sobrevivem a maior parte do tempo na rua e/ ou moram em abrigos.

Para complementar essa refl exão, caberia ainda um estudo no campo da sexual idade e das rel ações de gênero entre jovens de camadas popuI ares que ingressaram no mercado de trabal ho da indústria do lazer, tendo em vista que essas atividades têm possi bilitado o aumento do padrão de vida e um mai or acesso e interação com real idades diferenciadas. ${ }^{32}$

É válido acrescentar outros aspectos que perpassam a iniciação sexual feminina. Há val orização do vínculo conjugal e da maternidade, jogo de sedução, desejo e curiosi dade - uma menina virgem perguntou: "Pode acontecer de durante o beijo ficar mol hada?, Qual o prazer do homem no sexo?, Como é a primeira vez?" - e uma cultura de exibição de corpos - garotas passei am de short col ante e bustiê, adolescentes grávidas exi bem suas barrigas, garotos passeiam de calções com o torso nu. Em contraparti da, existe pouco diál ogo, dúvi das, controle famil iar, medo da gravi dez não pl anejada e da perda de um bem, a virgindade, que mantém um val or no mercado matrimonial nessa realidade.

Ao analisar a iniciação sexual e amorosa no Brasil e na França, Bozon \& Heil born (1996) sal i entam que a expressi vi dade corporal brasileira, contraposta à val orização da troca verbal na realidade francesa, insere-se em um universo social controlador que tem origem na herança de uma organização relacional e hierárquica da vida social, na qual os papéis de gênero são claramente del imitados.

Considerando que os contatos físicos conjugais movimentam-se em um sistema social potencialmente rígido, compreende-se por que tais práticas não aceleram a passagem para o ato sexual. Esse ponto de

\footnotetext{
${ }^{31}$ Ver comentário de Cunha (1997) sobre visão de moradores de uma favela do subúrbio e outra da Zona Sul carioca.

32 Para uma análise do papel dos movimentos musicais, como os bailes funk, na criação de oportunidades de trabal ho e ampliação de alternativas de vida para jovens de comuni dades carentes, ver Souto (1997). Com relação à real idade de Vigário Geral, vale citar que os jovens integrantes da banda musical local (Banda Afro Reggae), profissionalizaram-se e têm feito apresentações dentro e fora do país.
} 
vista oferece uma expl icação para a permanência (ai nda que tenha havido uma redução) do val or moral e social da virgindade feminina, como uma passagem essencial que leva à mudança no status social feminino. Exemplificando essa perspectiva, duas meninas responderam que a virgindade era o que el as tinham de maior val or na vida.

$N$ a trajetória dos rapazes, ao invés da virgindade, val oriza-se a experiência sexual. De acordo com o argumento proposto por Bozon \& Heil born (1996), nota-se que a ini ci ação sexual está relaci onada à aqui si ção da masculini dade, isto é, a consti tuição da identi dade masculina se dá por meio da afirmação da viril i dade. N esse uni verso, a ini ci ação amorosa conjugal e a aprendizagem sexual são fenômenos distintos, não fazem parte do mesmo cal endário, conforme expressa a diferenciação entre a namorada (moça direita, de família) e a 'outra' (safada, vadia, fácil).

No grupo em estudo, apenas dois declararam ser virgens, o mais novo deles, com 14 anos, e outro com forte adesão ao discurso religi oso católico. Para este, o ato sexual deve estar associado ao vínculo amoroso eà sintonia entre corpo e mente e não à pressão social. De preferência, o sexo deve ocorrer após o casamento, segundo recomenda a Igreja católica, mas ele admite que pode acontecer antes. O jovem canta na banda da igreja, não freqüenta bail le funk eé criticado por ficar dentro de casa. A importância da religião na sua vida aparece em vários momentos da entrevista:

Antigamente brigava com as pessoas, depois que entrei pra banda da igreja (...) fiquei um pouco mais calmo, até mesmo deixei de xingar palavrão (...) mudei. (...) Quando Deus achar que eu devo arrumar família e casar, aí eu caso. (M arcelo, 16 anos)

A despeito de tais evidências sugerirem uma vinculação entre o adiamento da iniciação sexual e a prática religiosa, tal associação não foi observada entre as meninas.

De acordo com a descrição das meninas que se declaram virgens, nos namoros preval ecem beijos, abraços e passei os. Outras atitudes como carícias dos órgãos genitais, sei os e sexo oral não foram citadas, sugerindo que tais práticas seriam posteriores à primeira penetração e não caracterizariam a iniciação sexual.

Todavia, nos encontros em grupo, os rapazes afirmaram que com a namorada virgem 'rolam' carícias e 'sexo nas coxas'. N a visão deles, isso não é sexo, sexo é penetração. A preocupação das garotas com os riscos do 'sexo na coxa', com os efeitos do 'remédio pra tirar o neném' e com a perda da virgi ndade - "Pode transar e conti nuar com a pel inha?" indica a presença destes comportamentos e ilustra os conflitos e dúvidas do processo de iniciação sexual feminino assinalado anteriormente. 


\section{Masturbação}

$\mathrm{N}$ ão é surpreendente registrar que a masturbação é mai s recorrente e aceita entre os homens. ${ }^{33}$ Seis garotos declararam que a praticaram; dois deles, al ém de duas meninas, continuavam a fazêlo. Houve aqueles que disseram que era uma questão de escol ha pessoal - "quem quer faz". Contudo, preval eceram as vi sões críticas, nas quais as práti cas autoeróticas eram associadas à fal ta ou ao problema com um(a) parcei ro(a). Algumas meninas relataram: "é estranho"; "não é legal, por que fazer sozinho se tem uma pessoa [com quem] você pode fazer o mesmo?"

Os comentári os mascul inos também apontam nessa direção:

O cara que faz isso tá com falta de mulher mesmo, ou meio tarado, ou a mulher dele não está satisfazendo ele dentro de casa. Eu acho que não é uma coisa legal. (Álvaro, 18 anos)

Pô, tem cara que, né, pra ele se contentar, só fazendo isso mesmo, né, porque agredindo não pega bem também, então o cara mesmo só, el e se masturbando mesmo. (Pedro, 18 anos)

Convém acrescentar que, durante a entrevista coletiva, a masturbação foi defini da como um 'recurso' diante da di ficuldade detransar com a namorada, devido à repressão da mãe da menina e/ou receio da moça de ficar com 'fama negativa'. Com base nos comentários dos rapazes, observa-se que a prática auto-erótica é percebi da como uma etapa da trajetória masculina relacionada à experimentação do sexo - "hoje não tem nada a ver, quando era pequeno fazia (Antônio, 16 anos); "normalmente com 13, 15 anos, depois que arruma parceiro, não faz mais" (Otávio, 19 anos) -, mas não está rel aci onada a uma afi rmação da vi rilidade.

De qual quer modo, a mai or familiari dade e aceitação dos rapazes com a masturbação e uma menor experimentação das moças refl ete a aceitação social do exercício sexual masculino de forma mais autônoma, isto é, desvinculada da reprodução e das rel ações estáveis. As restrições à masturbação indi cam que a visão moderna de val orização da descoberta e de exploração do prazer sexual individual ou compartilhado para al ém da penetração - presente no discurso preventivo sobre sexo mais seguro - não tem repercussão nesse universo.

${ }^{33} \mathrm{~N}$ a população francesa, Bozon (1995) evidenciou que, embora o percentual de homens, que afi rmam masturbar-se ser bem mai or do que o das mul heres, esta prática aumentou significativamente no grupo feminino (19\%, em 1971 e 71\%, em 1992), em parte, devido às transformações na sociedade e ao maior diálogo sobre sexualidade. Estas alterações apresentam variações entre grupos sociais da mesma sociedade e de contextos diversos. A percepção do grupo em foco ilustra este ponto de vista. 


\section{Sexo vaginal, anal e oral}

A primei ra rel ação sexual das meninas - associada por elas ao coito vaginal, ou mel hor, à perda da virgindade - ocorreu em torno dos 14 anos, em geral, com o namorado de uma fai xa etária mais al ta (por volta dos 20 anos), indi cando a rel ação entre sexo e vínculo amoroso. As motivações inserem-se em contextos diversos (desejo, curiosidade, afirmação frente ao grupo, conflitos familiares). Contudo, parecem ter em comum o val or simbólico de uma passagem para uma nova condição. As falas exemplificam:

Ele falava que eu não tinha nada a perder, que eu tinha que tirar minhavirgindade. $\mathrm{N}$ a hora eu fiquei com medo, mas depois o medo passou. (Valéria, 17 anos)

Estava querendo aprender, fazer o que as outras faziam. (M aria, 15 anos)

Foi uma situação de revoltamento que eu era moça e minha mãe fal ava que eu era mulher, aí eu peguei e pratiquei. (Letícia, 18 anos)

Grande parte das meninas entrevistadas sentiu dor ou medo; das dez garotas com experiência sexual, três (duas com 13 e uma com 15 anos) engravidaram na primeira rel ação, mas relataram ter perdido os bebês. A maioria sabia dos riscos ("nem pensei", "confiava nele"), mas apenas uma usou preservativo.

$\mathrm{N}$ a iniciação sexual dos meninos, preval eceu o ocasional e o inesperado - "rolou um clima", desejo, convite, "sal ada mista", ${ }^{34}$ curi osi dade -, ocorrendo por vol ta dos 13 anos com a namorada, colega ou caso. Em contraste com a reali dade feminina, o vínculo amoroso foi menos relevante. N enhum del es usou qual quer método.

Pesquisas no campo da prevenção da Aids, dirigidas a jovens brasilei ros (Santos, 1992; M érchan-Hamann, 1996; Paiva, 1996b), somadas ao número de casos de Aids e de gravidez precoce, sugerem a baixa freqüência do uso regular de camisinha entre adolescentes.

Dados da Secretaria Municipal da Saúde do Rio de Janeiro reveIam que a proporção de nasci dos-vivos de mães adol escentes residentes é de $18,69 \%$. O Ministério da Saúde divulgou que $23,44 \%$ dos partos realizados pel o Sistemaú nico de Saúde (SUS), em 1995, foram feitos em

\footnotetext{
${ }^{34}$ Sal ada mistaéuma brincadei ra de sortei o, na qual cada fruta (pera, uva, maçã) corresponde a uma situação (beijo no rosto, abraço e aperto de mão), sendo que a sal ada mista é beijo na boca.
} 
gestantes faixa de 15-19 anos (Brasil, 1996). ${ }^{35}$ Em 2000, o SUS real izou 645 mil partos de adolescentes entre 15 a 19 anos em todo o país.

As respostas às questões 'O que é sexo? Vocêjá fez sexo? Como e quando foi a sua primeira vez?' revelam que, para ambos, a iniciação sexual está relacionada ao primeiro coito vaginal e que o conceito de sexo está associado à penetração. A pergunta 'Que tipo de sexo você faz?' indica o predomínio do sexo vagi nal denominado de "comum", "normal", 36 "pela frente", "cobra com aranha"; "vaginal", "na vagina". A expressão "vaginal " ou "na vagi na" e as denomi nações dos órgãos genitai $s^{37}$ (vagi na e pênis foram os mais citados) indicam a presença da terminologia ci entífica (médi ca). Além disso, sugerem uma di ferenci ação em relação às demais práticas sexuais (sexo oral e anal ), seja para negá-las, seja para ampliar as opções nesse campo.

Os meninos admitem um repertório sexual mais amplo do que as meninas. Entre as variações, aparecem o sexo oral (apontado por al guns como a prática sexual preferi da) e combinações de ações diversas. Diante da não-caracterização das mesmas - "pratico todos os tipos" (Letícia, 18 anos); "faço tudo com mulé" (João, 19 anos); "tudo, não tenho preferência" (Vítor, 16 anos) -, não foi possível averiguar quais as práticas sexuais referi das.

O sexo anal foi citado por uma minoria. U ma menina (Teresa, 18 anos) di sse quetentou mas não gostou. Para um rapaz (M aurício, 15 anos), "depende da mulé (...) a vontade tem que ser dela, ela que tem que fal ar". Com base nessa afirmação, pode-se supor que o sexo anal é um sexo especial, que depende de uma negociação com a mul her. Os demais rel atos o associam à "nojeira" e a sexo com mulher "vadia": "Pro homem não é muito bom não, agora pra mulher é bom (...) a mulher fazer no homem, né. (...) o contrário é nojento" (Pedro, 18 anos).

Esta frase sugere que o sexo pode significar a penetração ou a fel ação. De acordo com o estudo de Paiva (1996a), 81\% dos estudantes do ensino fundamental da rede pública do sexo feminino nunca tinham praticado sexo anal; entre as universitárias da USP o percentual caía

\footnotetext{
35 Segundo Camarano (1998), entre as razões al egadas por jovens brasileiras para não utilizar métodos na primeira relação, mais de $40 \%$ declararam não esperar ter rel ações naquel e momento; cerca de $30 \%$ afirmaram desconhecer métodos e $6 \%$ al egaram desejo de ter filhos.

${ }^{36}$ Para um menino, "normal é quando a menina aceita fazer o que os dois querem", sugerindo referências ou experiências relacionadas à imposição do parcei ro masculino.

${ }^{37}$ Em menor proporção, apareceu xereca, xoxota, xana, cocota, urina, caixinha, Bráulio, peru; duas meninas não quiseram fal ar e um menino afirmou "como dizem os livros".
} 
para 52,1\%. N o universo dos homens, tal diferença opõe-se: o sexo anal não foi prati cado por 59,1\% dos uni versitários e por 39,6\% dos al unos do ensino fundamental. Tais dados podem indicar que o sexo anal é menos praticado por mulheres de camadas populares.

Todos os jovens entrevistados, de ambos os sexos, afirmaram que tiveram experiências heterossexuais, não havendo relatos de homoerotismo. As opiniões acerca da homossexuali dade apontam para duas vertentes opostas: uma, contrária à di scriminação, é centrada no di reito das escoI has e gostos pessoais: "cada um sabe de si "; "faz o que quer da vida", "tem seu gosto"; a outra, crítica e mais comum entre as mul heres, predomina a concepção de desvio e pecado: "esquisito"; "nojento"; "semvergonhice"; "errado, Deus fez o homem para a mulher".

Há registros de menor tol erância com as mulheres que transam com mulheres. Tais opi niões revel am visões ambíguas da homossexualidade: está longe da experiência pessoal dos jovens, mas presente em seu cotidiano por meio do contato com conhecidos, amigos ou familiares; é al go estranho, mas, ao mesmo tempo, deve ser tol erado em respeito às escol has individuais.

A partir de um levantamento com 602 estudantes, a maioria do ensino fundamental da rede pública de quatro municípios brasileiros, M ontei ro (1995) identificou que os adjetivos mais citados para caracterizar pessoas que preferem ter relações com pessoas do mesmo sexo foram: corajosas $(45 \%)$, infel izes $(37,5 \%)$ e loucas $(35,1 \%)$. Os dados sugerem que as práticas homossexuais são vistas como um enfrentamento da ordem social e sinal de descontentamento e desequilíbrio, refl etindo a noção de desvio. As concepções sobre práticas homoeróticas foram aprofundadas por Costa (1992) e Parker (1989).

Segundo um líder comunitário de 29 anos, na sua época, era comum os meninos se ini ciarem sexual mente com gays e profi ssionais do sexo, apesar de seus amigos muitas vezes não admitirem. A ausência dessa situação nas entrevistas pode ter ocorrido pelo constrangimento decorrente do preconceito social em torno do tema e/ou pelo aumento da aceitação social do sexo entre adolescentes e da forte associação entre homossexuali dade e transmissão do vírus da Aids.

Embora grande parte do grupo pesquisado tenha ressal tado a importância da camisinha na prevenção de doenças e da gravidez não planejada, e que praticamente todos soubessem onde consegui-la gratuitamente, apenas uma minoria afi rmou usá-la com regularidade. N o capítul o segui nte, será apresentada uma discussão sobre a lógica do uso e do não-uso do preservativo. 
As diferenças entre os gêneros ficam evidenciadas no mai or repertório sexual dos homens e no mai or número de parcei ras. As meninas afirmam que fazem sexo com o namorado/marido em média duas vezes por semana - há práticas (quase) diárias, princi pal mente entre as casadas -; os meninos comentam que transam com parcei ras diversas (namorada, "outras", "biscate") com freqüências variadas de um a todos os dias da semana.

A iniciativa, em geral, é do homem. Não obstante a maioria afirmar que os(as) meninos(as) têm o direi to de dizer não na prática sexual, os rel atos confirmam o papel do homem como protagonista, sempre disposto e interessado em sexo. Para al gumas moças, os homens não têm controle, são instintivos e têm mai s apetite sexual. N o universo masculino, há concordâncias quanto a este ponto de vista, condenação da expressão do desejo sexual feminino e afi rmação da dominação masculina (o homem é visto como o provedor, aquel e que "banca", o dono, o que tem poder). $O$ relato de Pedro, 18 anos, é il ustrativo:

Pô, mental idade de homem ébotar filho no mundo e sempretá ali com a obrigação dele trabal hando pra poder sustentar. A mentalidade da mul her não, a mental idade da mulher é ficar em casa né, tomando conta do filho, fazendo comida, lavando, passando (...) tem mulher que tenta fazer o que o homem faz aí acaba virando sapatão (...) quando eu fal o quero, tem que ser o que eu quero, né. Porque se for a pessoa que eu tô ali, que eu sempre tô bancando, então tem que ser o que eu quero, né. (...) Então se aquilo é nosso, aquilo tem que continuar sendo nosso. (Grifo meu)

Contudo, um del es argumentou que "mul her tem mais vontade" (João, 19 anos); outro questionou o peso do reconhecimento do apetite sexual mascul ino devido às cobranças de desempenho e di sponi bilidade constante. Álvaro, de 18 anos, esclarece:

O homem é mais assediado que a mulher, a mulher consegue se controlar. Quando ela quer dizer não, ela diz. (...) O homem não, sempre tem que dizer sim, aquela situação de machismo. (...) Se o homem fala que não tá a fim, a mulher já acha que ele tá com outra na rua.

As descrições das características dos gêneros mostram a presença da perspectiva hierárquica na percepção do grupo. Para as garotas, os homens são "safados", "imediatistas", gostam de briga, têm mais li berdade e devem trabal har. Em contraposição, as mulheres são definidas como "sofredoras", "esforçadas", "possessivas", "medrosas", "lentas" e pertencentes ao mundo doméstico. A classi ficação dos garotos reafirma esta visão. Essas opiniões se refletem na educação familiar, ambos os sexos 
admitem que menina é mais control ada e 'presa', ao passo que o menino é mais livre e 'solto'. A gravidez precoce dissociada da vida conjugal é uma das razões para o controle feminino. U m rapaz declarou: "[com] os meninos os pais não têm tanta dor de cabeça de pegar barriga, já as meninas podem arrumar namorado que não presta" (Álvaro, 18 anos).

Em seu estudo com mulheres de bai xo poder aquisitivo, Guimarães (1996) oferece um ponto de vista complementar, argumentando que a sexual i dade nesse uni verso se insere no model o da hierarquia e da reciprocidade do meio familiar. Dessa forma, diferencia-se dos valores do modelo indi vidual ista moderno que informam a sexual idade das camadas sociais médias. Nas suas palavras: "é o valor atri buído à família que constitui a referência axial da identidade da mulher, bem como norteia a ética e moral idade que Ihe é própria" (Guimarães, 1996:296). N o ideário moderno, a sexualidade não está subordinada ao sistema de gênero, tem um val or em si, fenômeno conectado com a concepção moderna deindi víduo, que sustenta a i gual dade e a simetria dos sexos (Fry, 1982).

Com base nos dados das trajetórias do grupo pesquisado apresentados até então, foi possível identificar ligações de densidade si mbólica nas quais o val or da proteção do universo masculino se conecta com o trabal ho no âmbito público, sustento financeiro, força física e bélica, enquanto as expectativas sociais em relação ao mundo feminino referem-se aos cuidados com os filhos, ao esteio moral e à ocupação e à organização do espaço doméstico.

No terreno das manifestações sexuais, o sentido de proteção apóiase na lógica das esferas de significação da 'casa' e da 'rua'. Os laços de parentesco e de vizinhança ('conheci do') aci onam a percepção de segurança e de confiança, justificando a prática sexual desprotegida. Em oposição, o estranho à comunidade ('desconheci do') representa o perigo e o sexo arriscado, esti mulando a adoção de práticas preventivas. Isso significa dizer que o "familiar tende a proteger", ao passo que o 'de fora' é percebido como ameaçador.

Observou-se que os núcleos si mból i cos de proteção do grupo estudado estão ancorados nas condições materiais e nas representações e práticas, confi guradoras das rel ações de gênero esexual idade, tai s como: a força moral , econômica e bélica do poder il egal , a deficiência do poder público e a di visão tradicional dos atributos femininos e masculinos.

Com intuito de aprofundar a reflexão sobre a caracterização de um sistema cultural de proteção, em seguida será anal i sada a percepção dos jovens em foco relativa aos cuidados de saúde, em especial, à prevenção do HIV e às ameaças do dia-a-dia. 